\title{
Epidemiología de las neoplasias mieloproliferativas crónicas (NMPC) en Colombia: primer reporte del registro colombiano de NMPC
}

- Virginia Abello Polo, Domingo Saavedra Ramírez, Mario Quintero, José Fernando Lobatón, Claudia Sossa, Diego Lopera, Guillermo Quintero, Ricardo Romero, Daniel Espinosa, Ángela Peña

Asociación Colombiana de Hematología y Oncología, Bogotá D.C.

Contacto: virginia.abello@gmail.com

Introducción y objetivos. Las NMPC son relativamente raras, con incidencias que varían entre 0,47-1,03/100.000 habitantes; es importante para el país conocer las características clínicas de estos pacientes. Este es el primer reporte del trabajo del registro colombiano de NMPC.

Materiales y métodos. Estudio multicéntrico, observacional, que incluye pacientes en forma retrospectiva y prospectiva en ocho centros del país, de abril de 2013 a diciembre de 2014; las variables cualitativas se presentan con frecuencias absolutas y relativas; y las cuantitativas se resumen en medidas de tendencia central.

Resultados. Once centros fueron aprobados, 8 ingresaron pacientes, se describen los primeros 179 casos. El $50 \%$ eran hombres, la edad promedio al diagnóstico 58,7 años (19-92), 93 son trombocitemia esencial (TE); 55, policitemia vera (PV); 31, mielofibrosis (MF). El 41\% tenía esplenomegalia al diagnóstico. El 20\% tuvo complicaciones trombóticas; el 12,85\%, sangrado. Solo en el $57,5 \%$ se realizó JAK, de ellos en un 53,5\% positivo, en especial solo el $60 \%$ de las PV. El $8 \%$ de los casos no tenían estudio de médula ósea, el 29,3\% tiene algún grado de fibrosis. El hallazgo más frecuente fue hiperplasia megacariocítica en el $59,78 \%$ de los casos. Más del $50 \%$ de pacientes estaban sintomáticos al diagnóstico. Solo el $11 \%$ no recibió tratamiento farmacológico, los más frecuentes fueron hidroxiurea en 149 y ASA en 79 casos. Con promedio de seguimiento de 52,6 meses; el $97,21 \%$ de los pacientes están vivos.

Conclusiones. Los hallazgos sugieren que algunas características de las NMPC podrían ser diferentes a lo reportado en otras series, validando la importancia del esfuerzo de recoger información local.

\section{Características clínicas y demográficas del cáncer de mama}

\section{Pedro Ramos}

Oncocare, Bogotá, D.C.

Contacto: pramos152@yahoo.com

Introducción y objetivos. El propósito de este estudio es describir las características clínicas y demográficas del cáncer de mama en una cohorte de 10 años.

Materiales y métodos. Se trata de un estudio descriptivo; se registró la información de las características clínicas y demográficas de 566 pacientes con cáncer de mama durante el período 2005-2014. Las pacientes fueron seguidas en intervalos cada 4 a 6 meses, en donde se documentaba el estado vital y la presencia de recaídas locales o sistémicas de la enfermedad. Se realizaron análisis descriptivos usando medidas de tendencia central, ubicación y dispersión para las variables continuas, y frecuencias absolutas y relativas para las variables categóricas.

Resultados. Se identificaron 566 pacientes con cáncer de mama, la edad promedio fue 57,9 años, se presentó en estado avanzado un $46,4 \%$, era receptor de estrógenos positivo el $72,4 \%$, HER2 positivo el $15,7 \%$, histología ductal infiltrante el $87,2 \%$, grado histológico II el 50,8\%, con compromiso ganglionar el 44,9\%, posmenopáusicas el $61,1 \%$. La quimioterapia neoadyuvante más utilizada fue esquemas AC (ciclofosfamida y doxorubicina) y ACT (ciclofosfamida, doxorubicina, paclitaxel). Las respuestas a la quimioterapia neoadyuvante son altas en orden del $70 \%$ al $80 \%$ dependiendo del esquema usado y respuestas completas entre el $10 \%$ al $25 \%$. Se observó una frecuencia de muertes del $16,5 \%$.

Conclusiones. El cáncer de mama es muy sensible al tratamiento de quimioterapia neoadyuvante con excelentes respuestas y relativa baja frecuencia de muertes. 